NBER WORKING PAPER SERIES

\title{
EMINENT DOMAIN VERSUS GOVERNMENT PURCHASE OF LAND GIVEN IMPERPECT INFORMATION ABOUT OWNERS' VALUATION
}

\author{
Steven Shavell \\ Working Paper 13564 \\ http://www.nber.org/papers/w13564 \\ NATIONAL BUREAU OF ECONOMIC RESEARCH \\ 1050 Massachusetts Avenue \\ Cambridge, MA 02138 \\ October 2007
}

I wish to thank the John M. Olin Center for Law, Economics, and Business at Harvard Law School for research support, Daniel Bachner and Zachary Gerson for research assistance, and Oliver Hart, Louis Kaplow, Daniel Kelly, Thomas Miceli, Rohan Pitchford, A. Mitchell Polinsky, Daniel Rubinfeld, Kathryn Spier, and Cass Sunstein for comments. The views expressed herein are those of the author(s) and do not necessarily reflect the views of the National Bureau of Economic Research.

(C) 2007 by Steven Shavell. All rights reserved. Short sections of text, not to exceed two paragraphs, may be quoted without explicit permission provided that full credit, including (C) notice, is given to the source. 
Eminent Domain Versus Government Purchase of Land Given Imperpect Information About

Owners' Valuation

Steven Shavell

NBER Working Paper No. 13564

October 2007

JEL No. D8,H1,H4,K11

\begin{abstract}
Governments employ two basic policies for acquiring land: taking it through exercise of their power of eminent domain; and purchasing it. The social desirability of these two policies is compared in a model in which the government's information about landowners' valuations is imperfect. Under this assumption, the policy of purchase possesses the market test advantage that the government obtains land only if an owner's valuation is low enough that he is willing to sell it. However, the policy suffers from a drawback when the land that the government needs is owned by many parties. In that case, the government's acquisition will fail if any of the owners refuses to sell. Hence, the policy of eminent domain becomes appealing if the number of owners of the land is large. This conclusion holds regardless of whether the land that the government seeks is a parcel at a fixed location or instead may be located anywhere in a region.
\end{abstract}

Steven Shavell

Harvard Law School

1575 Massachusetts Avenue

Hauser Hall 508

Cambridge, MA 02138

and NBER

shavell@law.harvard.edu 


\title{
Eminent Domain versus Government Purchase of Land

\author{
Given Imperfect Information About Owners' Valuations
}

\author{
Steven Shavell ${ }^{*}$
}

Governments employ two basic policies for acquiring land: taking it through exercise of their power of eminent domain; and purchasing it. The social desirability of these two policies is compared in a model in which the government's information about landowners' valuations is imperfect. Under this assumption, the policy of purchase possesses the market test advantage that the government obtains land only if an owner's valuation is low enough that he is willing to sell it. However, the policy suffers from a drawback when the land that the government needs is owned by many parties. In that case, the government's acquisition will fail if any of the owners refuses to sell. Hence, the policy of eminent domain becomes appealing if the number of owners of the land is large. This conclusion holds regardless of whether the land that the government seeks is a parcel at a fixed location or instead may be located anywhere in a region.

\section{Introduction}

Governments generally enjoy the ancient right of eminent domain, which is to say, the right to take land by fiat, usually on the condition that they pay fair compensation to the landowner. ${ }^{1}$ But governments may, of course, also obtain land by purchasing it, raising the question why governments need the right of eminent domain for land (and not for goods).

\footnotetext{
* Samuel R. Rosenthal Professor of Law and Economics, Harvard Law School, and Research Associate, National Bureau of Economic Research. I wish to thank the John M. Olin Center for Law, Economics, and Business at Harvard Law School for research support, Daniel Bachner and Zachary Gerson for research assistance, and Oliver Hart, Louis Kaplow, Daniel Kelly, Thomas Miceli, Rohan Pitchford, A. Mitchell Polinsky, Daniel Rubinfeld, Kathryn Spier, and Cass Sunstein for comments.

${ }^{1}$ On the right of eminent domain and the requirement to pay compensation in the legal system of the United States, see, for example, Dukeminier et al. (2006), ch. 12. On the history of eminent domain or its equivalents in the United States and other countries, see, for instance, Nichols (2006), sec. 1-1.

(C) 2007 Shavell, ALL RIGHTS RESERVED
} 
In this article, I consider an aspect of that question by comparing the social desirability of eminent domain to government purchase of land in a simple model of land acquisition. The key feature of the model is that the government's knowledge of landowners' valuations is imperfect. Under this assumption, the policy of purchase possesses the classic advantage that acquisition of land is subjected to the market test the government obtains a parcel of land only if its offer to an owner is high enough that the owner is willing to sell. In contrast, eminent domain involves no market test, implying that the government might turn out to take a parcel of land even though the social value of the land is lower than its private value. The policy of purchase suffers from a difficulty, however, when the land that the government requires is held by multiple owners, for then the government needs all the owners to sell in order to proceed (I assume that the government cannot undertake its project if it fails to obtain the entire parcel that it seeks). The necessity of such unanimity in owners' decisions to sell constitutes an acute disadvantage of the policy of purchase when the number of owners grows large, for in that context the likelihood that some owner will reject the government's price offer becomes high.

Consequently, the policy of eminent domain tends to be appealing in the model when the number of owners is large, whereas the policy of purchase tends to be better when the number of owners is low. This is the major conclusion of the present article, but as its summary below will make clear, the conclusion is qualified and amplified in important ways, especially in relation to whether the land the government requires is a specific parcel, only a contiguous parcel that may be located anywhere within a region, or only a parcel of given area that can be comprised of many dispersed subparcels. 
In Section 2 I state the main assumptions of the model. I suppose that the government places a social value on the land it needs and that the values that private owners place on the land are not observable to the government but are drawn from a known distribution. Under eminent domain, the government may take land from private owners but must pay appropriate compensation for doing so, ${ }^{2}$ where such compensation is interpreted as the expected private value of land. Under the policy of purchase, the government makes a single price offer for the land. If the government obtains the land, it realizes the social value of the land, but the payment that the government makes (in compensation for a taking or else in the purchase price) is assumed to involve a positive social cost of funds (because of the implicit cost of raising funds through taxation). The government acts to maximize social welfare.

In Section 3 I address the case where a single owner holds a specific parcel of land that the government seeks. Under the policy of eminent domain, the government will take the land if its social value minus the social cost of paying just compensation exceeds its expected private value. ${ }^{3}$ Under the policy of purchase, the government's social welfare-maximizing price offer must be positive but less than the social value of the parcel, owing to the social cost of funds. Purchase is often socially superior to eminent domain, the reason being the market test advantage of that policy, that when the

\footnotetext{
${ }^{2}$ I make the assumption that compensation must be paid because this is a legal requirement (see the previous note). It will be clear, however, that in the model that I examine, the policy of eminent domain without compensation would be superior to eminent domain with compensation, because the social cost associated with compensation (to be noted) would be avoided. Hence, the main conclusion that I reach concerning the superiority of eminent domain to purchase when the number of landowners is large would only be reinforced for eminent domain without compensation.

${ }^{3}$ Suppose that the government seeks an acre parcel with a social value of $\$ 1$ million, that the social cost of a dollar of funds is $\$ .10$, and that the expected private value of the acre is $\$ 100,000$. Then the government will take the acre, since its social value net of the social cost of paying $\$ 100,000$ in fair compensation would be $\$ 990,000$, which exceeds its expected private value of $\$ 100,000$.
} 
owner's value turns out to be high and government acquisition would not be socially desirable, the owner will reject the government's price offer. Still, it is possible that eminent domain would be superior to purchase because of a potential acquisition cost advantage enjoyed by the government under the former policy. Namely, under eminent domain, the government acquires land at a fair compensation cost equal to its expected value to owners, whereas under the policy of purchase the government may have to (and thus will find it desirable to) offer substantially more than the expected value of the land in order to acquire the land with high probability. ${ }^{4}$

In Section 4 I examine the case where multiple owners hold subparcels making up the parcel that the government wishes to obtain. In particular, I assume that there are $n$ owners and that their values per acre are independently and identically distributed. Under eminent domain, it is optimal for the government to take the parcel (meaning take all $n$ owners' subparcels) under the same condition as in the single owner case. Under the policy of purchase, the government's optimal price offer is positive but is not necessarily less than the social value of the land. The explanation of this somewhat counterintuitive observation that the optimal price offer might exceed the social value per acre is that such

\footnotetext{
${ }^{4}$ In the example of note 3, suppose that there are two possible owners' values: $\$ 50,000$, with probability 50\%; and $\$ 150,000$, with probability $50 \%$. Under eminent domain, the government would pay fair compensation of $\$ 100,000$. Under purchase, it can be verified that the government would choose the price offer of $\$ 150,000$ in order to obtain the land for sure. Thus, the acquisition cost - and therefore the social cost of funds - would be higher under the policy of purchase. Hence, social welfare would be lower under the policy of purchase. (In this example, note, there is no market test advantage of the policy of purchase because the distribution of values is discrete. In the model, however, there always is such an advantage because the distribution of owners' values is continuous and unbounded, but the possible advantage of eminent domain still exists.)
} 
a high offer may be useful in inducing every single owner to sell, as that is necessary for the government to acquire its parcel and for the social value of the parcel to be realized. ${ }^{5}$

With regard to the comparison of eminent domain versus purchase in the multiple owner case, eminent domain must be superior to purchase if the number of owners is sufficiently large, assuming that eminent domain leads to positive social welfare. The kernel of the argument for this conclusion (the central one of the article) is, as was mentioned, that the problem of making a price offer that all owners will accept becomes great as $n$ grows. In particular, I show that the probability of the government's making a successful purchase tends to zero with $n$ (even though the price is optimally adjusted as $n$ increases). Moreover, assuming that eminent domain improves social welfare in expected terms, the probability that eminent domain raises social welfare in fact tends to one with $n$. Thus, when the number of owners is large, the sense in which the policy of eminent domain can be superior to the policy of purchase is strong. ${ }^{6}$

In Section 5 I consider an extension of the model in which the government does not require a specific parcel of land but rather any parcel in a relevant region that is of the needed size. The main point demonstrated is that the conclusion that the policy of eminent domain is superior to purchase when the number of owners is sufficiently large continues to hold. One might think otherwise because, when the government can obtain

\footnotetext{
${ }^{5}$ In the example of note 3, the optimal offer per acre could exceed $\$ 1$ million, for instance, it could be $\$ 2$ million per acre. If there are many owners of the parcel that the government seeks, it could be likely that one among them would place a value on land of $\$ 2$ million per acre, and to induce him to sell, the offer per acre would have to be at least $\$ 2$ million. Such a high offer might not lead to very much inefficiency because most of the other owners who would accept the offer might be likely to place values on land that are below its social value of $\$ 1$ million per acre. The optimality of offers exceeding the social value of land is not anomalous, for I show under broad conditions that such an offer must be optimal as $n$ grows large.

${ }^{6}$ As I observe, however, this conclusion depends on the assumption that the government bears a positive social cost of funds. If the cost of funds were zero, then the policy of purchase would always be superior to eminent domain (the probability of successful purchase would not tend toward zero when government acquisition is desirable, because the optimal price offers of government would grow unboundedly with $n$ ).
} 
the land it needs anywhere within a region, it does not require unanimous approval of a price offer from a named group of owners. But if, as is assumed in this extension, the land that the government seeks is contiguous (for simplicity, it is a square), the government does require that some set of neighboring owners all give their approval to a price offer. ${ }^{7}$ This turns out to be an important enough hurdle that the policy of purchase will fail with high likelihood if the number of owners is sufficiently large. In consequence, the comparison of purchase and of eminent domain is qualitatively the same as in Section 4, in which the government needs a fixed parcel of land with multiple owners.

In Section 6, I consider an extension of the model in which the land that the government needs can be dispersed without affecting its social value. In this case, eminent domain does not become attractive as the number of owners becomes large because the government does not need the approval even of neighboring landowners the agreement to sell of any set of landowners of the requisite area will do.

In the conclusion, I comment on two final issues: the bearing of the analysis on the use of eminent domain on behalf of private developers; and the applicability of the analysis to property other than land (why does the government not need the right of eminent domain to obtain goods?).

Previous writing on eminent domain has not, to my knowledge, addressed the notion developed here that variability in individuals' valuations of land may lead to defeat of the policy of government purchase and may justify eminent domain when the

\footnotetext{
${ }^{7}$ I show that the problem of obtaining some group of neighboring owners all to give their approval is equivalent to that of obtaining a run of successes of length equal to a proportion of all trials in repeated Bernoulli trials.
} 
number of landowners is large. ${ }^{8}$ A problem facing a land assembler not addressed here is that of strategic holdout, namely, that landowners may delay and may negotiate for a high price in order to extract some of the surplus that would be gained by the assembler if it acquired their land. On this issue, see, for example, O'Flaherty (1995), Menezes and Pitchford (2004a, b), and Miceli and Segerson (2007). ${ }^{9}$ (The problem of land assembly examined here is different, and might be termed one of honest holdout, as it derives from the unwillingness of owners to sell for less than the true value of their land to them. ${ }^{10}$ ) Two additional articles of note on land acquisition and eminent domain are Blume, Rubinfeld, and Shapiro (1984) and Hermalin (1995). They address primarily the effect of the government's payment of compensation under eminent domain on the private investment incentives of a single landowner; they are not concerned with comparing eminent domain to a policy of purchase, and thus not with the bargaining problems that arise under purchase when there are multiple landowners. Also of note is Mailath and Postlewaite (1990), who show in a public goods model that when unanimous approval of a collective project is required and the government does not know individuals'

\footnotetext{
${ }^{8}$ However, Munch (1976), a largely empirical investigation of eminent domain, includes suggestive remarks (see pp. 476-479) about the problem of purchase when landowners' values vary.

${ }^{9}$ In the legal literature, see also Calabresi and Melamed (1972), especially at pp. 1106-1108, which informally discusses the problem of strategic holdout and the consequent need for eminent domain.

${ }^{10}$ Because the government makes a single offer to owners, they refuse to sell only if the offer is less than their valuation. The problem analyzed here arises despite the government having all the bargaining power; the problem is due to variation in owner land value and government lack of information about owner value. In contrast, the problem of strategic holdout can arise only where the government does not possess all the bargaining power, occurs even if owners are identical, would exacerbate the problem with purchase that I find, and adds to the advantages of eminent domain that I examine when the number of owners is large.
} 
valuations, the probability of efficient project adoption tends to zero as the number of individuals grows. ${ }^{11}$

\section{Assumptions and Framework of Analysis}

The government places a social value on a specific parcel of land that it needs to acquire, for instance, to build an airport at a particular location. For concreteness I often call the parcel an acre. Let

$s=$ social value of the acre of land needed by the government; $s>0$.

If the government does not acquire the full acre of land, it will obtain no value. This assumption is made to reflect situations in which it is important for the government to possess at least a threshold quantity of land (airplanes require at least a minimum amount of runway for takeoff and landing). ${ }^{12}$

Land is owned at the outset by private parties, called owners. An owner's value per acre of land is drawn from a distribution of possible values. Let

$$
v=\text { value per acre of land to an owner, }
$$

where

$$
\begin{aligned}
f(v)= & \text { probability density of } v, f(v)>0 \text { on }[0, \infty] \text { and } 0 \text { elsewhere; } F(v) \text { is the } \\
& \text { distribution function of } f(v) .
\end{aligned}
$$

The value $v$ is known to an owner but not observed by the government; the government knows $f$. Let

${ }^{11}$ A major difference between their article and this is that I show (in Section 5) that when unanimity is not required, but only the agreement of some adequate set of neighboring landowners, it is still true that the probability of efficient purchase of land tends to zero as the number of landowners grows. Other differences are that they require that budget balance holds, whereas I do not, and that I assume that there is a positive social cost of funds, whereas they do not.

${ }^{12}$ If I were instead to assume that the social value of land is rising and convex in the quantity of land, the qualitative results would be similar to those I find. 


$$
n=\text { number of owners. }
$$

In the case of $n>1$, multiple owners (each of whom owns a different subparcel, as described in section 4), the value per acre of the $i^{\text {th }}$ owner is denoted $v_{i}$, where the $v_{i}$ are independently drawn from the distribution with density $f^{13}$

Also, if the government acquires an owner's land and uses it to generate the social value $s$, the owner derives no benefit from $s$. The interpretation of this simplifying assumption is that a single landowner would be unlikely to capture more than a tiny fraction of the benefit from any particular public project that required his land (such as building a school).

Under the policy of eminent domain, the government may take land, and if so must pay to the owner(s) fair compensation, assumed to be the expected value of the land per acre, namely, $E(v)$, where $E$ stands for expectation. ${ }^{14}$

Under the policy of purchase, the government makes a single price offer to owners. Let $x=$ price offer of the government per acre. An owner will thus accept the offer if and only if $v_{i}<x .^{15}$ That there is a single offer applying to all $n$ owners is due to the assumption that the government cannot observe the $v_{i .}{ }^{16}$ I further describe the policy of purchase below.

\footnotetext{
${ }^{13}$ Note that one example is $v_{i}=k+\epsilon_{i}$, where $k$ is a common component of land value known to the government and $\epsilon_{i}$ is an unobservable idiosyncratic component.

14 The assumption that fair compensation is $E(v)$ rather than, say, some higher value is not essential; it will be seen that what is important about the assumption is that compensation is based on a population statistic rather than on observation of $v$.

${ }^{15}$ If $v_{i}=x$, the owner will be indifferent about accepting the offer, and I adopt the convention that he will not accept it. I make similar assumptions below without further comment.

${ }^{16}$ I remark on the outcome if the government could observe the $v_{i}$ at the end of Section 4.
} 
The government bears a positive social cost per dollar of funds, which may be interpreted as due to the administrative expense of taxation or to its distortionary effects.

Let

$c=$ social cost per dollar of government funds; $c>0$.

Social welfare $W$ equals the value of land (to whomever enjoys it) minus the social cost of government funds expended. The government acts to maximize social welfare by choosing between the policy of eminent domain and the policy of purchase (using each optimally). I do not investigate the choice between two more general classes of policies that the government might employ, namely, mechanisms in which (as in eminent domain) landowners' participation is not necessarily voluntary versus mechanisms in which (as in government purchase) landowners' participation is voluntary.

\section{A Single Party Owns The Land Sought By The Government}

Assume here that the acre needed by the government has one owner. This case is worth studying because important aspects of the comparison of eminent domain and purchase are best understood in isolation from issues concerning multiple owners.

Note that it is first-best for the government to obtain the land from the owner if and only if $s>v$.

Under eminent domain, if the government takes the land, social welfare will be (1) $s-c E(v)$

because the government will obtain the benefit $s$ from the land and incur the social cost $c E(v)$ from its payment of compensation of $E(v)$ for the taking. If the government does

not take the land, social welfare will be 
since the owner will make use of the land.

Under the policy of purchase, if the government's price offer is $x$, social welfare will be

$$
W(x)=F(x)(s-c x)+\int_{x}^{\infty} v f(v) d v
$$

because $x$ will be accepted when $v$ is below $x$ and rejected when $v$ is at least $x$. The government's problem is to maximize $W(x)$ over $x \geq 0$. Let $x *$ denote the optimal offer. ${ }^{17}$

The conclusions reached about the two policies are given below.

Proposition 1. (a) Under the policy of eminent domain, land is taken if and only if its social value $s$ is sufficiently high, if and only if $s>(1+c) E(v)$.

(b) Under the policy of purchase, the optimal offer $x *$ is positive, so that land is purchased with positive probability, and $x *$ is less than the social value of land $s$. In particular, $x^{*}$ satisfies $x=[s-c F(x) / f(x)] /(1+c)$.

(c) The social welfare comparison of the policies of eminent domain and of purchase is as follows:

(i) If the social value of land $s$ does not exceed $(1+c) E(v)$, so that under eminent domain there would not be a taking, then purchase is superior to eminent domain.

(ii) Otherwise, either policy could be superior; and in particular, purchase is superior to eminent domain for all $c$ sufficiently low (given $s$ ), and eminent domain is superior to purchase for all $s$ sufficiently high (given $c$ ).

Let me now discuss these conclusions. The proofs of conclusions that are not shown below are given in the Appendix.

\footnotetext{
${ }^{17}$ The optimal offer might not be unique, but for expositional ease I will describe it as if it were.
} 
With regard to eminent domain and part (a), it follows from (1) and (2) that under eminent domain, the government will take land if and only if

$$
s>(1+c) E(v)
$$

which is to say, when its social value exceeds the expected private value multiplied by the factor $(1+c)$, reflecting the social cost of funds.

With regard to purchase and part (b), it can be shown that the problem of maximizing (3) over offers $x$ has a solution $x^{*}$. The derivative of (3) with respect to $x$ is

$$
W^{\prime}(x)=[s-(1+c) x] f(x)-c F(x)
$$

which is positive at $x=0$. Hence, $x^{*}$ must be positive. The explanation is that, regardless of $s$, there will be some chance that $v$ is less than $s$, in which case government acquisition of land would be desirable if the social cost of funds $c$ were not positive. But no matter how high $c$ is, if the offer $x$ is sufficiently low, the social cost of funds will be outweighed by the social value of the land. Since $x^{*}$ is positive, we know that the optimal $x^{*}$ is determined by the first-order condition

(6) $[s-(1+c) x] f(x)-c F(x)=0$,

so that $x *$ must satisfy

(7) $x=[s-c F(x) / f(x)] /(1+c)<s$.

The intuition explaining that $x *<s$ is as follows. If $x=s$ the allocation of land would be ideal, so that there would be no first-order loss in social welfare from lowering $x$ (owners just induced to refuse the offer would obtain values only slightly below $s$ ). But there would be a first-order social savings achieved from lowering $x$ because $c$ is positive and the government spends less when its bid is accepted. Note too that, if $c$ is zero, (7) implies that $x^{*}=s$ and the first-best outcome would result. 
To compare social welfare under the two policies, assume first that $s$ is low enough that (4) does not hold, meaning that under eminent domain there will be no taking. Then, under eminent domain social welfare will be $E(v)$. Under the policy of purchase, however, social welfare will be higher. To show this, observe that $W(0)=E(v)$, for if an offer of 0 is made, no owner will accept it. But I noted above that $W^{\prime}(0)>0$. Hence social welfare must exceed $E(v)$ at $x^{*}$. The explanation is that, under the policy of purchase, there is a positive probability that the owner's value will be lower than $x^{*}$ and land will be acquired by the government; in other words, the market test advantage sometimes results in a beneficial acquisition under the policy of purchase.

Now assume that (4) holds, so that under eminent domain there will be a taking and social welfare will be $s-c E(v)>E(v)$. Let me first show that for all low $c$, purchase is superior to eminent domain; the underlying reason is that for low $c$ the market test advantage, which allows individuals with high $v$ to retain their land, is more important than the social cost of paying for land. In particular, if $c$ is 0 , social welfare under purchase exceeds social welfare under eminent domain: under purchase $x *$ is $s$, so purchase is made if and only if $s>v$ and the first-best outcome is achieved; under eminent domain, land is taken; hence, social welfare is higher under purchase by the amount (8) $\int_{S}^{\infty} v f(v) d v>0$

It follows that social welfare must be higher under purchase than under eminent domain for all $c$ sufficiently low, since social welfare under each policy is continuous in $c$.

Let me now explain why eminent domain might be superior to purchase. As mentioned in the Introduction, the answer concerns a potential cost advantage to the 
government. Specifically, when the government takes land under eminent domain, it pays $E(v)$, but when the government purchases land at its optimal offer price $x^{*}$, this offer may well exceed $E(v)$, and significantly so, because such an offer might be needed to obtain land with a high likelihood given the dispersion of the distribution of owners' values $v$. To illustrate, consider for simplicity a discrete distribution of $v$ (like that in note 5): $v$ is 50 with probability .5 and 150 with probability .5 , so $E(v)=100$; the social value $s$ is 1,000 , and $c$ is .1 . Under eminent domain, taking land and paying compensation of $E(v)=100$ is optimal and social welfare is $s-c E(v)=1,000-.1(100)=990$. Under the policy of purchase, the government's optimal offer is 150 , because the government will wish to obtain the land with certainty rather than only with probability .5. Hence, social welfare is $1,000-.1(150)=985$. Social welfare is lower because the government has to pay (and wants to pay) more, 150, in order to obtain the land for sure. The acquisition cost advantage of eminent domain in a case like this constitutes a social welfare advantage because the cost $c$ of funds is positive.

The intuition behind the foregoing discrete example suggests why it is true that if $s$ is sufficiently high, eminent domain will be superior to purchase. If $s$ is high, it will be socially desirable for the offer price $x^{*}$ to be high, and higher than $E(v)$, implying that there will be a cost advantage obtained under eminent domain. It is true that the market test advantage will be lost under eminent domain. But as $s$ grows, the market test advantage becomes insignificant in importance, because the probability that an owner's value $v$ would exceed $s$ tends toward 0 .

\section{Multiple Parties Own The Land Sought By The Government}


Now assume that there are $n$ individual owners of subparcels making up the acre parcel of land needed by the government. The owners' values per acre are $v_{l}, \ldots, v_{n}$, which, recall, are independent draws from the distribution $F$, a random sample from $F$. For simplicity, I suppose that each owner's subparcel is $1 / n$ of the acre. ${ }^{18}$ (Equivalently, as can be readily verified, I could suppose that each owner's subparcel is 1 acre and that the government seeks a parcel of $n$ acres that has the social value $s n$. Thus, one can think of the multiple owner case as arising either when the parcel sought by the government is of given size but happens to be owned by many owners of small subparcels, or when the parcel sought by the government happens to be larger and thus is more likely to be owned by many owners of usual size subparcels.)

Note that it is first-best for the government to acquire the acre if and only if $s>$ $v_{1} / n+\ldots+v_{n} / n=\left(v_{1}+\ldots+v_{n}\right) / n$, that is, if and only if $s$ exceeds the sample mean.

Under eminent domain, I assume that if the government exercises its right to appropriate land, it takes the entire acre and pays each of the $n$ owners $(1 / n) E(v)$, as this is the expected value of each subparcel. ${ }^{19}$ Hence, if the government takes land, its total payment to the $n$ owners is $E(v)$. Accordingly, if the government takes the acre, social welfare is $s-c E(v)$, which is (1). If the government does not take the land, social welfare is $E\left(v_{1} / n+\ldots+v_{n} / n\right)=E(v)$, which is (2). Thus, social welfare when there is a taking and when there is not is the same as in the single owner case.

\footnotetext{
${ }^{18}$ The results to be obtained in this section do not depend on that assumption, but the notation would become more burdensome were individual owners' parcel sizes to vary.

${ }^{19}$ I do not consider the exercise of eminent domain in order to take less than the entire acre because the assumption is that the social value of less than the entire acre is 0 .
} 
Under the policy of purchase, I assume that the government's offer $x$ holds only if all owners accept it, that is, if any owner rejects $x$, the government pays no one and all owners retain their land. ${ }^{20}$ The probability that the offer of $x$ per acre is accepted by all owners is $F(x)^{n}$. In this event each owner receives $(1 / n) x$, so that the total payment of the government is $x$. Hence, if the offer $x$ is accepted by all owners, social welfare is $s-c x$. If $x$ is not accepted by all owners, social welfare is $v_{1} / n+\ldots+v_{n} / n$. The integral of social welfare when $x$ is not accepted by all owners can be expressed as

$$
\text { (9) } \begin{aligned}
\int_{0}^{\infty} \ldots \int_{0}^{\infty}\left[v_{l} / n\right. & \left.+\ldots+v_{n} / n\right] f\left(v_{1}\right) \ldots . f\left(v_{n}\right) d v_{1} \ldots d v_{n} \\
& -\int_{0}^{x} \ldots \int_{0}^{x}\left[v_{l} / n+\ldots+v_{n} / n\right] f\left(v_{1}\right) \ldots . f\left(v_{n}\right) d v_{1} \ldots d v_{n} .
\end{aligned}
$$

To explain, the first term is the sum of the $n$ owners' values of their $1 / n$ acre subparcels under all possible outcomes of the $v_{i}$, and the second term is the sum of the owners' values when all owners accept $x$, so the difference must be the sum of owners' values when not all of them accept $x$. The first term in (9) equals $E(v)$, and the second term reduces to $n$ similar terms, the first of which is

$$
\begin{aligned}
& (1 / n) \int_{0}^{x} \ldots \int_{0}^{x} v_{l} f\left(v_{l}\right) \ldots . f\left(v_{n}\right) d v_{l} \ldots d v_{n} \\
& =(1 / n) \int_{0}^{x} v_{l} f\left(v_{l}\right) d v_{l}\left(\int_{0}^{x} f\left(v_{2}\right) d v_{2}\right) \ldots\left(\int_{0}^{x} f\left(v_{n}\right) d v_{n}\right)=(1 / n) F(x)^{n-1} \int_{0}^{x} v_{l} f\left(v_{l}\right) d v_{l} .
\end{aligned}
$$

There are $n$ such terms, adding to

(11) $F(x)^{n-1} \int_{0}^{x} v f(v) d v$.

${ }^{20}$ If the government were to pay owners who accepted its bid when not all owners accepted, the analysis would not be qualitatively different, because, as will be seen, the key point of this section is that the government needs all owners to accept to obtain the social value from the land. 
Hence, social welfare under purchase given $x$ equals

(12) $W_{n}(x)=F(x)^{n}(s-c x)+\left[E(v)-F(x)^{n-1} \int_{0}^{x} v f(v) d v\right]$.

The government's problem is to maximize $W_{n}(x)$ over $x \geq 0$.

The results in this $n$ owner case are as follows, where $x^{*}(n)$ denotes the optimal offer given $n$.

Proposition 2. (a) Under the policy of eminent domain, land is taken if and only if its social value $s$ is sufficiently high, if and only if $s>(1+c) E(v)$.

(b) Under the policy of purchase,

(i) the optimal offer $x *(n)$ is positive, so that land is purchased with positive probability, and $x^{*}(n)$ may exceed the social value of land $s$. In particular, $x *(n)$ satisfies (13).

(ii) As $n$ grows, the optimal offer $x *(n)$ tends to a limit $x * *$ determined by (15), where $x^{* *}>x^{*}(1)$ and where $x^{* *}>s$ for all $c$ sufficiently low. Also, as $n$ grows, the probability of successful purchase $F\left(x^{*}(n)\right)^{n}$ tends to 0 .

(c) The social welfare comparison of the policies of eminent domain and purchase is as follows:

(i) If the social value of land $s$ does not exceed $(1+c) E(v)$, so that under eminent domain there would not be a taking, then purchase is superior to eminent domain.

(ii) If $s$ exceeds $(1+c) E(v)$, then either policy could be superior; and in particular, purchase is superior to eminent domain for all $c$ sufficiently low (given $s$ ), and eminent domain is superior for all $s$ sufficiently high (given $c$ ). 
(iii) If $s$ exceeds $(1+c) E(v)$, then for all $n$ sufficiently high, eminent domain is superior to purchase. Indeed, as $n$ grows, the probability that eminent domain is socially desirable tends to 1 , whereas the probability that purchase would be successful tends to 0.

Let me explain and comment on these conclusions. ${ }^{21}$

Part (a) is clear, for social welfare if there is taking and if not is as previously discussed in Section 3.

With regard to part (b), it can be shown that the problem of maximizing $W_{n}(x)$ has a solution $x^{*}$.

That $x^{*}$ must be positive is essentially for the reason given in respect to Proposition 1. Namely, regardless of $s$, there will be some chance that the mean of the $v_{i}$ is less than $s$, in which case government acquisition of land would be first-best; and no matter how high $c$ is, if the offer $x$ is sufficiently low, the social cost of funds will be of second-order significance.

Why, however, might $x *$ exceed the social value $s$ of land, that is, why might it be desirable for government to offer more than the land is worth? In the case of a single owner, it was not desirable for the government's offer $x$ to exceed $s$, for such an offer could only result in a welfare-lowering purchase from an owner with a $v>s$. In the case here of multiple owners, however, an $x>s$ may be needed to induce a high $v_{i}$ owner to accept, along with others whose $v_{i}$ are low and for that reason make government acquisition of the entire acre of land socially worthwhile. ${ }^{22}$

\footnotetext{
${ }^{21}$ Again, all claims not shown here are demonstrated in the Appendix.

${ }^{22}$ A closely related point is that in the multiple owner case, confronting each owner with a price $s$ would not create the first-best desirable test for government acquisition of land, because the first-best test is
} 
Consider the following discrete example with two owners: ${ }^{23} v$ is 1 with probability .9 and 11 with probability $.1, s$ is 10 , and $c$ is .01 . There are thus three pairs of possible values of $v_{1}$ and $v_{2}:(1,1)$, with probability $.81 ;(1,11)$, with probability .18 ; and $(11,11)$, with probability .01 . Observe that it is first-best for the government to acquire the acre when the two owners' values are $(1,1)$ and $(1,11)$, for then the average values per acre are 1 and 6 , respectively, below the social value of 10 for the acre; and it is first-best for the owners to retain their land when their values are $(11,11)$, for then their average value per acre is 11 , exceeding the social value. Now compare the two possible offers $x$ of 1 and $11 .{ }^{24}$ If $x=1$, both owners will accept and the government will purchase the land only when the pair is $(1,1)$; social welfare will be $.81(10-1-.01)+$ $.18(6)+.01(11)=8.47$. If $x=11$, both owners will always accept; social welfare will be $10-.01(11)=9.89$, which is higher. The reason that social welfare rises when the offer is 11 - which exceeds the social value of 10 - is that an offer of 11 is necessary for a successful purchase when the pair is $(1,11)$, in order to attract the owner whose value per acre is 11 . Further, this purchase is socially desirable because the other owner's value is low (making the average value 6 , less than the social value of 10). It is true that an offer of 11 also results in a socially undesirable purchase when the owners' values are $(11,11)$, but this is a relatively unlikely event (its probability is .01, as opposed to the probability of .18 of $(1,11))$. The intuition of this example underlies the result in part (iii) that, for all $n$ sufficiently large, the optimal offer $x *(n)$ must exceed $s$ if $c$ is not too high. That is,

whether the sum $v_{l} / n+\ldots+v_{n} / n>s$, or equivalently, whether $v_{l}+\ldots+v_{n}>n s$. This socially desirable test is clearly different from the test whether for a particular owner $i, v_{i}>s$. Moreover, $v_{l}+\ldots+v_{n}>n s$ more often than when $v_{i}>s$ for all $i$.

${ }^{23}$ It will be clear that a similar continuous example would also result in an $x^{*}>s$.

${ }^{24}$ It is obvious that an offer higher than 1 and less than 11 cannot be optimal, as it would be accepted in the same circumstances as an offer of 1 but cost the government more. 
provided that $c$ is not too high, when there are many buyers, it is always desirable to raise the offer somewhat above $s$ in order to attract some high value owners, because they will be likely to be accompanied by other low value owners.

The first-order condition determining $x^{*}$, from differentiating $W_{n}(x)$, is

$$
F(x)^{n-1} f(x)[n(s-c x)-x]-c F(x)^{n}-(n-1) F(x)^{n-2} f(x) \int_{0}^{x} v f(v) d v=0
$$

The first term reflects the marginal expected benefit from raising $x$ when bids are accepted. The second term is the marginal social cost due to the government's having to pay inframarginal individuals a higher amount. The third term measures the expected loss from the fact that when the marginal person is attracted to make a purchase, he brings with him $n-1$ other owners who no longer derive values from their land. Equation (13) can be rewritten as

$$
(s-c x)=c F(x) /(n f(x))+x / n+[(n-1) /(n F(x))] \int_{0}^{x} v f(v) d v
$$

As $n$ grows large, (14) tends to

$$
(s-c x)=F(x) \int_{0}^{x} v f(v) d v
$$

This can be shown to have a unique solution $x^{* *}$ to which $x^{*}(n)$ tends as $n$ grows.

That $x^{* *}>x^{*}(1)$ is explained by the fact that as $n$ grows, it becomes more difficult to attract all the owners to accept, because some owner is likely to have a high value $v_{i}{ }^{25}$ Also, the closely-related intuition that I gave for why an offer exceeding $s$ is

\footnotetext{
${ }^{25}$ This intuition also suggests that $x^{*}(n)$ is increasing in $n$, but I have not been able to establish
} this. 
possible would seem to be more important the higher $n$ is; this helps to explain the result that $x^{* *}>s$ for all positive $c$ sufficiently low.

That the probability of a successful purchase $F\left(x^{*}(n)\right)^{n}$ tends to 0 is due to the fact that, as $n$ grows large, the odds of some person placing a high value on his property that exceeds the government's bid rise. Of course, the optimal bid $x *(n)$ is chosen taking into account the presence of $n$ owners, but the problem of obtaining acceptance from all $n$ remains. The proof follows from the point that $x^{*}(n)$ tends to a finite limit $x^{* *}$, implying that $\lim _{n \rightarrow \infty} F\left(x^{*}(n)\right)^{n}=\lim _{n \rightarrow \infty} F\left(x^{* *}\right)^{n}=0$.

Now let us turn to the social welfare comparison of eminent domain and purchase. Claims (i) and (ii) are explained essentially as in the single owner case. For given $n$, purchase must be superior to eminent domain if under eminent domain, there would not be a taking - which is when $s<(1+c) E(v)-$ for under purchase there is always some positive probability of purchase and of raising social welfare above the status quo, due to the market test advantage (however attenuated this is, due to there being $n$ owners). And if under eminent domain $s$ is high enough that there would be a taking, either purchase or eminent domain could be superior, the latter being possible mainly because under eminent domain there is a possible cost-saving advantage relative to purchase.

Claim (iii), that when there would be a taking under eminent domain, eminent domain is superior to purchase for all $n$ sufficiently high embodies the advantage of eminent domain in the many owner context. This is, in a sense, the central conclusion of the present article. The reasoning is as follows. Under eminent domain, social welfare is $s-c E(v)$, which exceeds $E(v)$ by the hypothesis that there would be a taking under eminent domain. But under the policy of purchase, we know that the probability of 
successful purchase tends to 0 , meaning that social welfare tends to $E(v)$. Hence, if $n$ is sufficiently high, social welfare under purchase must be lower than under eminent domain.

It was also asserted in the claim that not only is eminent domain superior in expected value to purchase for $n$ sufficiently high, but also the probability that the exercise of eminent domain is socially desirable tends to 1 . This follows from several observations. The law of large numbers tells us that, for any $\epsilon>0$, the probability that the sample mean $\left(v_{1}+\ldots+v_{n}\right) / n$ lies within $\epsilon$ of $E(v)$ tends to 1 with $n$. Let $\epsilon=.5[s-$ $c E(v)-E(v)]$, which is positive by hypothesis. Hence, the probability that $s-c E(v)>\left(v_{1}\right.$ $\left.+\ldots+v_{n}\right) / n$ tends to 1 with $n$. But this means that the probability that a taking is socially desirable tends to 1 with $n$.

The preceding point and the point that $F(x *(n))^{n}$ tends to 0 with $n$ mean that, as $n$ grows large, the likelihood that purchase will result in acquisition of land goes to 0 , whereas the likelihood that a taking would be desirable goes to 1 . Therefore, the sense in which eminent domain is superior to purchase is, as stated in the Introduction, very strong.

Last, let me remark on the importance of three assumptions to the results in Proposition 2. One assumption is that $c>0$. This assumption was needed for the limiting results of (b)(ii) and (c)(iii). That is because, if $c=0$, the $x^{*}(n)$ do not tend to a 
positive limit; they rise unboundedly if $s>E(v) .{ }^{26}$ In effect, there is no problem with offers failing when $n$ grows because the government can raise its bid $x$ without incurring any social cost. For that reason, when $c=0$, eminent domain does not become superior to purchase when $n$ grows; purchase is superior to eminent domain. ${ }^{27}$

The second assumption is that the distribution of $v$ is unbounded. If $v$ instead had an upper bound $b$, then $x *(n)$ might equal $b$ for $n$ sufficiently high, so that the probability of a successful purchase might be 1 rather than tend to 0 with $n$. However, were that so, it would still be true that eminent domain would be superior to purchase, for eminent domain would involve lower cost to the government $(E(v)$ rather than $b)$.

The third assumption is that $v$ is not observable to the government. If $v$ were observable and the government could perfectly price discriminate, then the policy of purchase would be unambiguously superior to eminent domain regardless of the number of landowners. The proof is as follows. Under purchase, the government's optimal policy would be to make the minimum offer $v_{i}$ to each of the $n$ landowners if and only if this would raise social welfare, which is to say, if and only if the $v_{i}$ are such that $s-c\left(v_{1}+\right.$

${ }^{26}$ If $c=0$, then it can be shown that a solution $x^{*}(n)$ exists. To do so, it can be verified that the derivative of social welfare, the left-hand side of (13), is negative for $x$ exceeding $s n$. Hence one may restrict attention to $x$ in $[0, s n]$, a compact set, implying that $x^{*}(n)$ exists. To prove that the $x^{*}(n)$ rise unboundedly with $n$, it suffices to show that, for any $b>0$, the derivative of social welfare must be positive for all $x$ in $[0, b]$ if $n$ is sufficiently large. Now when $c=0$, the derivative of social welfare is, from (13),

$$
F(x)^{n-2} f(x)\left\{F(x)[n s-x]-(n-1) \int_{0}^{x} v f(v) d v\right\} .
$$

The integral above is less than $F(x) E(v)$, so the above expression exceeds $F(x)^{n-2} f(x)\{F(x)[n s-x]-(n-$ 1) $F(x) E(v)\}=F(x)^{n-2} f(x)\{F(x)[n s-x]-(n-1) F(x) E(v)\}=F(x)^{n-1} f(x)\{n s-x-(n-1) E(v)\}$. But $n s-x-$ $(n-1) E(v)=(n-1)(s-E(v))+s-x$. Because $s>E(v)$, it is clear that if $x \leq b,(n-1)(s-E(v))+s-x$ must be positive for all $n$ sufficiently high, implying that $x^{*}(n)$ must exceed $b$ for all $n$ sufficiently high.

${ }^{27}$ That purchase is superior to eminent domain follows from the fact that a price offer of $n s$ results in higher social welfare than eminent domain. To show this, note that if $n s$ is the offer, then the government does not acquire its parcel if and only if there is a landowner for whom the value exceeds $n s$. But when that is so, social welfare would fall due to government acquisition, since the landowner's value alone exceeds $(1 / n)(n s)=s$. Hence, social welfare under eminent domain must be lower than social welfare if the offer is $n s$. 
$\left.\ldots+v_{n}\right) / n>\left(v_{1}+\ldots+v_{n}\right) / n$. This policy results in greater social welfare than other pricing policies, and in particular, than offering $v_{i}$ to each landowner all the time. But the latter policy is equivalent to the use of eminent domain, as it would definitely result in acquisition of the acre and in expected expenditures of $E(v)$.

\section{Land Parcel Sought By The Government Can Be Located Anywhere}

In the above analysis the land that the government sought was a specific parcel.

Here, however, I assume that the land sought by the government can be located anywhere in a relevant region. This assumption reflects the common situation in which the government can make roughly equivalent use of differently situated parcels (airports might have approximately comparable value if located within 30 miles of a city and within a few miles of a major highway).

The chief reason that the assumption that the land can be located anywhere is of analytical interest is that, as mentioned in the Introduction, one might think that under it the central result that eminent domain is superior to purchase when the number of landowners grows large would not hold. That is, because the government does not need any particular group of landowners to unanimously accept its price offer in order to purchase a parcel of the kind it seeks - the consent of any group of landowners of such a parcel will do - one might believe that the policy of purchase would not tend be dominated by eminent domain when the number of landowners grows. However, this intuition is incorrect. The conclusion that eminent domain is superior to purchase if the number of owners is sufficiently large continues to hold.

To amplify, I assume here that the government needs to obtain a square parcel, with a side of $k$, where $0<k \leq 1$ and the square parcel can be located anywhere in the 
square acre of area 1. If the government makes a price offer and it obtains acceptances for more than a square parcel that it needs, I assume that it buys only what it needs (choosing any square of side $k$ from the accepted parcels). Otherwise, I retain the assumptions from above. I restrict attention here to proving the limiting result from Proposition 2 (although most of the other results from above carry over as well ${ }^{28}$ ). The conclusion to be proved is this.

Proposition 3. Suppose that the government seeks a square parcel of side $k$, where $1 \geq k>0$, where the square can be located anywhere in the unit acre and oriented in any direction. Then Proposition 2(c)(iii) holds. Namely, if $s$ exceeds $(1+c) E(v)$ (implying that a taking would raise social welfare), then for all numbers $n$ of landowners sufficiently high, eminent domain is superior to purchase. Indeed, the probability that eminent domain is socially desirable tends to 1 , whereas the probability that purchase would be successful tends to 0 .

Note that this proposition is quite general as it implies that if the government seeks a parcel that has any minimum contiguous part, the government will tend to fail under the policy of purchase and must use eminent domain if the number of landowners is sufficiently large. This is because, if the parcel sought by the government is required to have any contiguous part of minimum size, it must contain a square of at least $k$ for some positive $k$.

The strategy of the proof presented in the Appendix is to demonstrate that for the government to be able to purchase a square of side $k$ is equivalent to its obtaining a type of run of successes in Bernoulli trials, where the probability of success in each trial is the

\footnotetext{
${ }^{28}$ It is clear that Proposition 1 and Proposition 2(a) and 2(c)(i)-(ii) would hold by the logic of arguments already made. Proposition 2(b) would hold in modified form (conditions (13) and (15) would be altered).
} 
probability that its offer of $x$ is accepted by an owner. The reason that purchasing a square is equivalent to achieving a run of successes, rather than only a number of possibly separated successes, is in essence that the owners of the square are neighboring, meaning that they will occur in a row in an ordering of the landowners. Furthermore, the length of the run of successes must be such as to cover a certain proportion $q>0$ of all landowners, for the square of side $k$ covers a proportion $\left(k^{2}\right)$ of the region of area 1 .

From the foregoing argument, we know that for the government to acquire the square it needs, it must achieve a run of successes in $n$ trials of length at least $q n$. (This, note, is a generalization of the fact that, in section 4 where the government had to acquire a specific parcel, it had to achieve a run of $n$ successes in $n$ trials.) But the probability of such a run tends to 0 as $n$ becomes large. For instance, consider the probability of a run of heads in coin tosses of length at least $10 \%$ of all the tosses ( $q$ is .1). If the number of tosses is not large, say, 20 , then the probability of the run would be high, for the run of heads need only be 2 (that is, .1x20) in length. If, however, the number of tosses is 100,000 , the run of heads would have to be 10,000 in length, an extremely unlikely event. I verify in the Appendix that the probability of a run of successes of length at least $q n$ tends to 0 as $n$ grows, as long as $q>0$, where $1>p>0$ is the probability of success in a single trial.

Because the probability of a run of successes of the required nature tends to 0 with $n$, the probability that the policy of purchase results in acquisition of the square of land tends to 0 as $n$ increases, whereas eminent domain by definition will succeed and is socially desirable, because of the hypothesis that $s>(1+c) E(v)$. Moreover, the law of 
large numbers implies, as in Proposition 2, that the probability that a taking is socially desirable approaches 1 as $n$ grows.

Thus, the qualitative result that the policy of purchase fails and that eminent domain is desirable when the number of owners grows sufficiently large holds when the government seeks essentially any kind of contiguous parcel in a region.

\section{Land Parcel Sought By The Government Can Be Dispersed}

Suppose here, unlike in previous sections, that the land that the government needs to acquire can be dispersed. In particular, suppose that the government seeks a parcel of area $a$, where $0<a<1$, and where the social value of the land is as no matter how the area $a$ is comprised. Otherwise, I maintain the assumptions from above.

Intuition suggests that if the number of landowners $n$ grows, eminent domain will not necessarily become appealing, unlike in sections 4 and 5. The reason is that because the land the government purchases can be arbitrarily fractionated, the government will not have to obtain agreements to sell from any specific group of landowners or even from any neighboring group of them. Indeed, the law of large numbers suggests that as the number of landowners grows, the actual distribution of their values will approach the true distribution $F$, so that if the government bids $x$, it will obtain approximately the fraction $F(x)$ of land from those owners placing the lowest values on their land. Hence, the policy of purchase should be superior to eminent domain if the area $a$ sought is sufficiently small, allowing the government to make its purchase at a price less than $E(v)$.

To confirm these intuitions, let me now describe social welfare under the policy of purchase and under the eminent domain and then compare the policies. 
Under the policy of purchase, if the percentage of acceptances of a government price offer is at least $a$, the government can undertake its project because of the assumption that the government can make use of any subparcels comprising land area of $a$. Define $v(a)$ as the $v$ such that $F(v)=a$. It is shown in the Appendix, that a sequence of price offers $v(n)$ exceeding $v(a)$ can be constructed such that: the $v(n)$ tend toward $v(a)$ with $n$; the probability of successful acquisition of area $a$ tends to 1 with $n$; and social welfare under the price offer sequence tends with $n$ to the level of social welfare that the government would obtain if it offered the price $v(a)$ and precisely the fraction $a$ of landowners accepted, namely,

$$
[\operatorname{sa}-\operatorname{cav}(a)]+\int_{v(a)}^{\infty} v f(v) d v=a[s-c v(a)]+\int_{v(a)}^{\infty} v f(v) d v
$$

If the government does not purchase area $a$, social welfare is $E(v)=\int_{0}^{\infty} v f(v) d v$.

Hence, as long as

$$
s-c v(a)>E(v \mid v<v(a)),
$$

it is better in the limit for the government to purchase $a$ than not to do so. Notice that (17) states that the net social return per acre exceeds the expected return conditional on $v$ being less than $v(a)$, for only owners with valuations below $v(a)$ accept the government price.

Under eminent domain, a taking results in social welfare (regardless of $n$ ) of

$$
[s a-c a E(v)]+(1-a) E(v)=a[s-c E(v)]+(1-a) E(v) .
$$

Hence, it is better for the government to take land than not provided that

$$
s-c E(v)>E(v)
$$

To compare purchase when $n$ grows to eminent domain, consider the difference in social welfare under the policies assuming that the government acquires land under each. 
It will be optimal for the government to acquire land under each policy if (17) and (19) hold. Observe that (19) implies (17) if $v(a)<E(v)$, which is to say, if $a<F(E(v))$. Now, subtracting (18) from (16), we obtain

$$
a c[E(v)-v(a)]+(1-a)[E(v \mid v \geq v(a))-E(v)] .
$$

The first term is an advantage of purchase as long as $a<F(E(v))$, when $a$ can be purchased at a price per acre less than $E(v)$. The second term is always an advantage of purchase, because under the policy of purchase the remaining land area $(1-a)$ is the highest valued land, whereas under eminent domain it is only average value land (because the land that is taken is average value). Consequently, we have

Proposition 4. Suppose that the government seeks a parcel of area $a$, where $1>a$ $>0$, and where the social value of the area $s a$ does not depend on its location or how dispersed the area is. Then, Proposition 2(c)(iii) does not hold. In particular, if $s$ exceeds $(1+c) E(v)$ (implying that a taking would raise social welfare), it is not true that for $n$ sufficiently high, eminent domain is necessarily superior to purchase. Indeed, if $a<$ $F(E(v))$, purchase is superior to eminent domain for all $n$ sufficiently high.

Note that in this section, if the government makes offers of (slightly more than) $v(a)$, it will obtain area $a$ with a probability approaching 1 as the number of landowners grows, by the law of large numbers. Thus, for example, if $a$ were $20 \%$ of the land area, the government would be able to acquire that area with a price of about $v(.2)$ with a probability tending to 1 as $n$ grows. In contrast, in section 5 , even if the goal of the government were to acquire a much smaller square parcel, say a parcel with an area of only . $1 \%$ of the land area, the government would fail to acquire that relatively tiny parcel with a probability approaching 1 as $n$ grows. The resolution of these apparently 
conflicting outcomes is that, as $n$ grows, the success of the government in acquiring $20 \%$

of the land area must come about through the purchase of many separated parcels.

\section{Concluding Comments}

Use of eminent domain by private developers. The main point analyzed in this article, that when the number of landowners grows, it becomes more difficult to obtain a parcel through purchase, and that that might justify the use of eminent domain, would seem to apply to private developers of land as well. That is, it might be socially desirable to allow developers to borrow the power of eminent domain when they have to assemble large tracts of land held by many owners, because they would confront a problem in acquiring the required subparcels through purchase. ${ }^{29}$ In reality, the law sometimes does allow private parties to enjoy the right of eminent domain in roughly these circumstances. $^{30}$

Applicability of the analysis to property other than land. The analysis in this article has been interpreted as applying to land, but in what respects does it apply more generally? The single owner analysis of section 3 applies to any type of property; there is no particular reason to view it as bearing only on land. Hence, the point made there that purchase is an advantageous policy of government unless the social value of the property

${ }^{29}$ Were one to analyze this situation, one would have to take into account two differences from the situation that I considered. First, the private cost of spending a dollar for the developer is a dollar, instead of the presumably smaller social cost of raising a dollar of funds through taxation. This difference between the private and social cost of funds would seem to lead the developer to offer less than the government for land, and thus would apparently exacerbate the problem of failure to obtain land through purchase. Second, the social cost of funds for the developer is zero, since the funds are not raised through taxation, also suggesting that the circumstances under which acquisition of land by the developer would be desirable would be more broad than by the government.

${ }^{30}$ Notably, the law has granted railroads, utility companies, and, sometimes, private developers of substantial parcels who have a public purpose the right to take land via eminent domain. See, for example, Kelly (2006). 
is very high in relation to the distribution of private values pertains to property in general, and has a rough consistency to the fact that the law gives the government the right to seize property other than land in certain (mainly emergency) situations. ${ }^{31}$

The analysis of the multiple owner case, however, is special to land, or at least best fits land. In particular, the assumptions of section 4 - that the government needs all of the subparcels making up a specific parcel of land (or the assumption of section 5 that the government needs contiguous parcels) in order to obtain the social benefit from the parcel, and that there is significant variation in the values different owners attach to the land - do not seem natural to make for most other kinds of property. Suppose that the government wants a material, like steel. It would be unlikely that both of the foregoing assumptions would be valid, namely, that the government's benefit would be enjoyed mainly only if it obtained at least a threshold quantity of steel, and also (and more importantly) that there would be many owners of that quantity of steel all of whom would have to sell in order for the government to succeed. Hence, the central point of this article, concerning the need for eminent domain in the multiple owner context, seems to be relevant mainly to land.

31 This has occurred during wars and other armed conflicts, natural disasters, fires, and various crises. See, for example, Scheiber (2003). 


\section{References}

Blume, Lawrence, Daniel L. Rubinfeld, and Perry Shapiro. 1984. The Taking of Land: When Should Compensation Be Paid? Quarterly Journal of Economics. 99: 7192.

Calabresi, Guido, and A. Douglas Melamed. 1972. Property Rules, Liability Rules, and Inalienability: One View of the Cathedral. Harvard Law Review. 85: 1089-1128.

Dukeminier, Jesse, James E. Krier, Gregory S. Alexander, Michael H. Schill. 2006. Property. $6^{\text {th }}$ Edition. Aspen, New York.

Hermalin, Benjamin E. 1995. An Economic Analysis of Takings. Journal of Law, Economics, and Organization. 11: 64-86.

Kelly, Daniel. 2006. The "Public Use" Requirement in Eminent Domain Law: A Rationale Based on Secret Purchases and Private Influence. Cornell Law Review. 92: 1-65.

Mailath, George J., and Andrew Postlewaite. 1990. Asymmetric Information Bargaining Problems with Many Agents. Review of Economic Studies. 57: 351-367.

Menezes, Flavio, and Rohan Pitchford. 2004. A Model of Seller Holdout. Economic Theory. 24: 231-253.

---------. 2004. The Land Assembly Problem Revisited. Regional Science and Urban Economics. 34: 155-162.

Miceli, Thomas J., and Kathleen Segerson. 2007. A Bargaining Model of Holdouts and Takings. American Law and Economics Review.

Munch, Patricia. 1976. An Economic Analysis of Eminent Domain. Journal of Political Economy. 84: 473-498.

Nichols on Eminent Domain. 2006. Matthew Bender \& Company. New York.

O'Flaherty, Brendan. Land Assembly and Urban Renewal. Regional Science and Urban Economics. 1994. 24: 287-300.

Scheiber, Harry N. 2003. Property Rights versus "Public Necessity": A Perspective on Emergency Powers and the Supreme Court. Journal of Supreme Court History. 28: 339-369. 


\section{Appendix}

Proofs of claims not demonstrated in the text are given here.

\section{Proposition 1.}

Part (b): The only claim that needs to be shown is that there exists a solution to the government's problem of choosing a price offer $x \geq 0$ to maximize social welfare $W(x)$. To prove existence of a solution, it suffices to demonstrate that there exists a $t$ such that if $x>t$, then $W(x)<W(0)$. For then we know that to maximize $W(x)$, we can restrict attention to $x$ in $[0, t]$, and since $W(x)$ is continuous in $x$, it must have a maximum in a closed interval such as $[0, t]$. Now let $t=s / c$. Then if $x>t$, social welfare must be negative whenever $x$ is accepted, because the social cost of the purchase will exceed $c(s / c)=s$. Hence, $W(x)<E(v)=W(0)$.

Part (c)(ii): The claim that needs to be shown is that for all $s$ sufficiently high, eminent domain is superior to purchase. This is proved in five steps. Denote the optimal $x^{*}$ given $s$ by $x^{*}(s)$.

(1) $x^{*}(s)$ grows unboundedly with $s$; that is, for any $y>0, x^{*}(s)>y$ for all $s$ sufficiently high: We have that (7), determining $x^{*}(s)$, may be rewritten as (A1) $x=s /(1+c)-[c /(1+c)][F(x) / f(x)]$.

Let $m(y)$ be the maximum of the term $[c /(1+c)][F(x) / f(x)]$ over $x$ in $[0, y]$. I claim that if $s>(y+m(y))(1+c)$, then $x^{*}(s)>y$. If this is not true, $x^{*}(s) \leq y$ and (A1) must then be satisfied at some $x$ in $[0, y]$. But if $x$ is in $[0, y]$, the right side of (A1) must exceed (A2) $[(y+m(y))(1+c)] /(1+c)-m(y)=y+m(y)-m(y)=y$, implying that (A1) cannot be satisfied at $x$ in $[0, y]$, a contradiction.

(2) The probability of purchase tends to 1 as $s$ grows; that is, $\lim _{s \rightarrow \infty} F\left(x^{*}(s)\right)=1$ : This follows immediately from step (1).

(3) For any $y>0$, first-best social welfare $W^{*}$ exceeds social welfare under purchase $W(x *(s))$ by at least $c y$ for $s$ sufficiently high: Social welfare under purchase is obviously lower than $W^{*}$ by at least the expected social cost of purchase, $F\left(x^{*}(s)\right) x^{*}(s) c$. By step (1), there exists a threshold $t_{1}$ such that if $s>t_{1}$, then $x^{*}(s)>2 y$ (let $2 y$ play the role of $y$ in step (1)). By step (2), there exists a threshold $t_{2}$ such that if $s>t_{2}$, then $F\left(x^{*}(s)\right)>.5$. Let $t=\max \left(t_{1}, t_{2}\right)$. Then if $s>t$, we know that $F\left(x^{*}(s)\right) x^{*}(s) c>.5(2 y) c=$ $c y$, so that $W^{*}$ exceeds $W\left(x^{*}(s)\right)$ by at least $c y$.

(4) First-best social welfare $W^{*}$ minus social welfare under eminent domain tends to $c E(v)$ as $s$ grows: For $s>(1+c) E(v)$, we know that a taking is desirable under eminent domain, and let us assume that $s$ is this high. Then $W^{*}$ minus welfare under eminent domain is

$$
\int_{s}^{\infty}(v-s) f(v) \mathrm{d} v+c E(v),
$$

which tends to $c E(v)$ as $s$ grows.

(5) If $s$ is sufficiently high, eminent domain is superior to purchase: This follows from steps (3) and (4). In particular, choose $y=2 E(v)$. Then by step (3), $W^{*}$ minus welfare under purchase is at least $2 c E(v)$ for all $s$ sufficiently large. By step (4), for any positive $\epsilon, W^{*}$ minus welfare under eminent domain is within $\epsilon$ of $c E(v)$ for all $s$ 
sufficiently large. Hence, choosing $\epsilon$ to be small, it follows that for all $s$ high enough, welfare under eminent domain must exceed welfare under purchase.

\section{Proposition 2.}

Part (b)(i): We first need to show that a solution to the problem of choosing the optimal offer exists. This follows from the argument of Proposition 1 that in the problem with one owner an optimal $x$ exists, since again it is clear that the optimal $x$ cannot exceed $s / c$.

We next must show that $x^{*}(n)>0$. This follows because social welfare is higher for any positive $x<s /(1+c)$ than for $x=0$ : If $x<s /(1+c)$, then $x<s-c x$. This implies that if $n$ individuals accept $x$, social welfare must rise $(s-c x$ is social welfare, whereas if individuals keep their land, social welfare is bounded by $x$ ). Since the probability of acceptance of an offer is positive for any positive $x$, social welfare must be higher for any positive $x<s /(1+c)$ than for $x=0$.

Part (b)(ii): We first want to show that (15) has a unique solution $x^{* *}$. This is clear, since at $x=0,(s-c x)$ is $s$ and the right side of $(15)$ is 0 , and since $(s-c x)$ is decreasing in $x$ and negative for $x$ sufficiently high, whereas the right side is positive and increasing in $x$.

We next want to show that $\lim _{n \rightarrow \infty} x^{*}(n)=x^{* *} \cdot{ }^{32}$ Let us rewrite (14) and (15) as

$$
0=c F(x) /(n f(x))+x / n+[(n-1) /(n F(x))] \int_{0}^{x} v f(v) d v-(s-c x)
$$

$$
0=F(x) \int_{0}^{x} v f(v) d v-(s-c x)
$$

Observe first that the right side of (A4) must converge uniformly to the right side of (A5) over any closed interval $[0, t]$. That is, for any $\epsilon>0$, if $n$ is sufficiently high, the righthand side of (A4) will be within $\epsilon$ of the right side of (A5) for all $x$ in $[0, t] .{ }^{33}$ Let $t$ be $s / c$, so that the right side of (A4) must converge uniformly to the right side of (A5) in [0, $s / c]$, and recall from the proof of (b)(i), that $x^{*}(n)$ must be in $[0, s / c]$. Now to establish the claim, it must be shown that for any small $\delta>0, x^{*}(n)$ will be within $\delta$ of $x^{* *}$ for all $n$ sufficiently large. We know that over the interval $\left[0, x^{* *}-\delta\right]$, the minimum distance from 0 of the right side of (A5) is positive, say, $b_{1}$, since (A5) has a unique solution, and similarly over the interval $\left[x^{* *}+\delta, s / c\right]$, the minimum distance of the right side from 0 is positive, say $b_{2}$. Let $b=\min \left(b_{1}, b_{2}\right)$, so that the distance of (A5) from 0 over the two intervals is at least $b$. Since the right side of (A4) converges uniformly to the right side of

\footnotetext{
${ }^{32}$ If $x^{*}(n)$ is not unique, choose any optimal $x^{*}(n)$ as the element in the sequence of $x^{*}(n)$.

${ }^{33}$ The difference between the right sides of (A4) and (A5) is

$$
c F(x) /(n f(x))+x / n-\int_{0}^{x} v f(v) d v /(n F(x))=c F(x) /(n f(x))+x / n-E[v \mid v \leq x] / n,
$$
}

which is of the form $g(x) / n$, where $g(x)$ is continuous. Since $|g(x)|$ has a maximum $M$ over $[0, t]$, the distance between the right sides of (A4) and (A5) on $[0, t]$ is bounded by $M / n$. Hence, if $n>M / \epsilon$, the distance is bounded by $M /(M / \epsilon)=\epsilon$. 
(A5), if we choose $\epsilon=b / 2$, we know that for $n$ sufficiently large, the right side of (A4) must be within $b / 2$ of (A5) in $[0, s / c]$. But this implies that the right side of (A4) cannot equal 0 in $\left[0, x^{* *}-\delta\right]$ or in $\left[x^{* *}+\delta, s / c\right]$. Hence, the right side of (A4) can equal 0 only within $\delta$ of $x^{* *}$, which is to say, $x^{*}(n)$ must be within $\delta$ of $x^{* *}$.

Now let us demonstrate that $x^{* *}>x^{*}(1)$. To do this, it suffices to show that the left side of (15), $(s-c x)$, exceeds the right side when evaluated at $x^{*}(1)$, since as noted the left side is decreasing in $x$ and the right side is increasing in $x$. Now from (6), which determines $x *(1)$, we have

(A6) $s-c x=c F(x) / f(x)+x$.

But

(A7) $c F(x) / f(x)+x>x=x F(x) / F(x)>\int_{0}^{x} v f(v) d v / F(x)>F(x) \int_{0}^{x} v f(v) d v$,

which is the right side of (15).

We next show that $x^{* *}>s$ for $c$ sufficiently low. To prove this, it suffices to demonstrate that the left side of (15) exceeds the right side when evaluated at $x=s$ for $c$ sufficiently low. We know that the right side of (15) at $s$ is less than $F(s) s<s$, and thus the left-hand side $s-c s$ must exceed the right-hand side for all $c$ sufficiently low.

Finally, that the probability of successful purchase $F\left(x^{*}(n)\right)^{n}$ tends to 0 is clear since $x^{*}(n)$ tends to a limit $x^{* *}$, and $F\left(x^{* *}\right)<1$.

Part (c)(i): That purchase is superior to eminent domain if $s \leq(1+c) E(v)$, follows from the result (b)(i) that $x^{*}(n)>0$, for then $W_{n}\left(x^{*}(n)\right)>W_{n}(0)=E(v)$, which is social welfare under eminent domain given the hypothesis about $s$.

Part (c)(ii): To show that if $s>(1+c) E(v)$, purchase is superior to eminent domain for $c$ sufficiently low, it suffices to demonstrate that purchase is superior to eminent domain when $c=0$, since $W_{n}\left(x^{*}(n)\right)$ is continuous in $c$. When $c=0$, we have (see (13))

$$
W_{n}(x)=F(x)^{n-2} f(x)\left[F(x)(n s-x)-(n-1) \int_{0}^{x} v f(v) d v\right],
$$

from which it is clear that $W_{n}(x)$ is decreasing for $x \geq n s$. Also, when $c=0$,

$$
\left.\lim _{x \rightarrow \infty} W_{n}(x)=\lim _{x \rightarrow \infty}\left\{F(x)^{n} s+E(v)-F(x)^{n-1} \int_{0}^{x} v f(v) d v\right]\right\}=s .
$$

Hence, $W_{n}(n s)>s$, and thus $W_{n}\left(x^{*}(n)\right)>s$. But $s$ is social welfare under eminent domain. In other words, social welfare is higher under purchase than under eminent domain when $c=0$.

To prove that eminent domain is superior to purchase for all $s$ sufficiently high, we proceed in five steps; the proof is analogous to that in Proposition 1.

(1) $x^{*}(s)$ grows unboundedly with $s$; that is, for any $y>0, x^{*}(s)>y$ for $s$ sufficiently high: Choose some positive $s$, say $s_{0}$. Now to prove that $x^{*}(s)>y$ for $s$ sufficiently high, it suffices to prove only that $x^{*}(s)$ cannot lie in $\left[x^{*}\left(s_{\mathrm{o}}\right), y\right]$ for $s$ sufficiently high. This will suffice because we already know that $x^{*}(s)>x^{*}\left(s_{\mathrm{o}}\right)$ for $s>s_{\mathrm{o}}$, 
since $x^{*}(s)$ is increasing in $s^{34}$ To prove that $x^{*}(s)$ cannot be in $\left[x^{*}\left(s_{0}\right), y\right]$ for $s$ sufficiently high, we show that (13) cannot be satisfied in $\left[x^{*}\left(s_{\mathrm{o}}\right), y\right]$ if $s$ is sufficiently high. To do this, we demonstrate that

$$
F(x)^{\mathrm{n}-1} f(x)[n(s-c x)-x]-c F(x)^{n}-(n-1) F(x)^{n-2} f(x) \int_{0}^{x} v f(v) d v>0
$$

for $x$ in $\left[x^{*}\left(s_{0}\right), y\right]$ if $s$ is sufficiently high. This is true since the first term of (A10) grows unboundedly with $s$. In particular, let $m$ be the minimum of $F(x)^{n-1} f(x)$ over $\left[x^{*}\left(s_{0}\right), y\right]$. Thus, for $x$ in $\left[x^{*}\left(s_{0}\right), y\right]$, the first term is at least $m[n(s-c y)-y]$, which grows unboundedly with $s$. The other terms do not depend on $s$ so must be exceeded by the first term for $s$ sufficiently high.

(2) The probability of purchase tends to 1 as $s$ grows; that is, $\lim _{s^{\rightarrow \infty}} F\left(x^{*}(s)\right)^{n}=1$ : This follows from step (1).

(3) For any positive $y$, first-best social welfare $W^{*}$ exceeds social welfare under purchase by at least $c y$ for all $s$ sufficiently high: Social welfare under purchase is lower than $W^{*}$ by at least the expected social cost of purchase, $F\left(x^{*}(s)\right)^{n} c x^{*}(s)$. By step (1), there exists a threshold $t_{1}$ such that if $s>t_{1}$, then $x^{*}(s)>2 y$. By step (2), there exists a threshold $t_{2}$ such that if $s>t_{2}$, then $F\left(x^{*}(s)\right)^{n}>.5$. Let $t=\max \left(t_{1}, t_{2}\right)$. Then if $s>t$, we know that $F\left(x^{*}(s)\right)^{n} c x^{*}(s)>.5 c(2 y)=c y$, so that $W^{*}$ exceeds social welfare under purchase by at least $c y$.

(4) First-best social welfare minus social welfare under eminent domain tends to $c E(v)$ as $s$ grows: For all $s$ above $(1+c) E(v)$, we know that a taking is desirable under eminent domain, and let us assume that $s$ is this high. Then $W^{*}$ minus welfare under eminent domain is

$$
\left.\int_{0}^{\infty} \ldots \int_{0}^{\infty} \int_{s-\left(v_{2}+\ldots+v_{n}\right)}^{\infty}\left[\left(v_{1} / n+\ldots+v_{n} / n\right]\right)-s\right] f\left(v_{1}\right) f\left(v_{2}\right) \ldots . f\left(v_{n}\right) d v_{1} d v_{2} \ldots d v_{n}+c E(v) .
$$

The first term is the integral of the social loss when there is a socially undesirable taking, that is, when $v_{l} / n+\ldots+v_{n} / n \geq s$. This term tends to 0 as $s$ grows. Hence $W^{*}$ minus welfare under eminent domain tends to the cost of compensation $c E(v)$ as $s$ grows.

(5) If $s$ is sufficiently high, eminent domain is superior to purchase: This follows from steps (3) and (4). In particular, choose $y=2 E(v)$. Then by step (3), $W^{*}$ minus social welfare under purchase is at least $2 c E(v)$ for all $s$ sufficiently large. By step (4), for any positive $\epsilon, W^{*}$ minus welfare under eminent domain is within $\epsilon$ of $c E(v)$ for all $s$ sufficiently large. Hence, choosing $\epsilon$ to be small, it follows that for all $s$ high enough, welfare under eminent domain must exceed welfare under purchase.

Part (c)(iii): We need to prove that if $s$ exceeds $(1+c) E(v)$, then for all $n$ sufficiently high, eminent domain is superior to purchase. Social welfare under purchase is

(A12) $W_{n}\left(x^{*}(n)\right)=F\left(x^{*}(n)\right)^{n}\left(s-c x^{*}(n)\right)+E(v)-F\left(x^{*}(n)\right)^{n-1} \int_{0}^{x *(n)} v f(v) d v$.

\footnotetext{
${ }^{34}$ We know that $x^{* \prime}(s)>0$ because the partial derivative of the left side of (13) with respect to $s$ is
} positive. 
Since $x^{*}(n)$ tends to $x^{* *}$ as $n$ grows by part (b), $W_{n}\left(x^{*}(n)\right)$ tends to $E(v)$. However, social welfare under eminent domain is $s-c E(v)>E(v)$. Hence, if $n$ is sufficiently high, social welfare under eminent domain exceeds social welfare under purchase.

\section{Proposition 3.}

The sequence of increasing numbers of owners of land will for convenience be taken to be a sequence of successively finer partitions of the unit acre constructed as follows. The first partition in the sequence is obtained by dividing the unit square in half by a line going down its middle. Thus, the first partition has two partition elements (two subparcels held by different owners), each a rectangle that is $1 / 2$ in width and 1 in length. The second partition is obtained by taking each of the two rectangles in the first partition and dividing it into two squares by drawing a line horizontally across it. Thus, the second partition has four elements, each a square with side $1 / 2$. Continuing in this way, we obtain partitions that are successively finer, where the following is true. The $n^{\text {th }}$ partition, has $2^{n}$ partition elements, each with area $1 / 2^{n}$. In every odd numbered partition, the elements are rectangles with sides of length $1 / 2^{(n+1) / 2}$ and $1 / 2^{(n-1) / 2}$; and in every even numbered partition, the elements are squares with sides of length $1 / 2^{n / 2}$.

The proof consists of five steps.

(1) Let $n$ be the number of repeated independent trials, in each of which there are two possible outcomes, success or failure, and in which the probability of success in a trial is $p$, where $1>p>0$. Let $q$ be a proportion, where $1>q>0$. Let $P(n)$ be the probability of a run of consecutive successes of at least $q n$ in length. Then $\lim _{n \rightarrow \infty} P(n)=$ 0 : Denote by $i(q n)$ be the lowest integer greater than or equal to $q n$, so that the run of successes must be at least $i(q n)$ in length. The probability that there is a run of $i(q n)$ successes beginning in the first trial, and allowing for any outcomes (including a longer run) otherwise is $p^{i(q n)}$. Similarly, the probability that there is a run of $i(q n)$ successes stretching from the second trial up to trial $i(q n)+1$, and allowing for any outcomes otherwise (including a longer run beginning earlier or ending later) is also $p^{i(q n)}$. Because there are $n-i(q n)+1$ such originating points for runs of at least length $i(q n)$, the probability $P(n)$ of a run of at least length $i(q n)$ must be less than $(n-i(q n)+1) p^{i(q n)}$ : for the $n-i(q n)+1$ events under discussion not only include all the ways in which there could be a run of length at least $i(q n)$, but also the events are not mutually exclusive. (For example, a run of length $2 i(q n)$ beginning at trial 1 would be included in the first event, the second, ..., as well as the $i(q n)^{\mathrm{th}}$.) Now let $T(n)=(n-i(q n)+1) p^{i(q n)}$. Then (A13) $T(n+1) / T(n)=[(n+1-i(q(n+1))+1) /(n-i(q n)+1)]\left[p^{i(q(n+1))} / p^{i(q n)}\right]$. It is clear that the first term in brackets tends to 1 as $n$ grows. Observe that $i(q(n+1))$ equals either $i(q n)$ or $i(q n)+1$. Hence, the second term in brackets is either 1 or $p$, where $p$ must occur with regularity, since $i(q(n+1))$ will be 1 higher than $i(q n)$ with a frequency of about $1 / q$. This implies that, for high $n$, the sequence of ratios $T(n+1) / T(n)$ is approximately a sequence of 1's and $p$ 's, where $p$ occurs with a constant frequency. It follows that $T(n)$ tends to 0 with $n$ and thus that $P(n)$, being less than $T(n)$ tends to 0 with $n$.

(2) For the government to purchase a square parcel of side $k$ when it makes an offer of $x$ to owners in the $n^{\text {th }}$ partition, it must achieve a run of successes of at least $q 2^{n}$ in length in $2^{n}$ independent trials, where the probability of success in a trial is $F(x)$ and 
where $q>0$ and is independent of $n$ : Suppose that the acre is partitioned into squares of side no more than $k / 4$. Then it is clear from geometry that if the government acquires a square of side $k$, it must entirely contain some square of side at most $k / 4$. Let $n_{\mathrm{o}}$ be the first even numbered partition with squares of side less than or equal to $k / 4$. Thus, if the government acquires its parcel, some square in the $n_{\mathrm{o}}$ partition must be entirely contained in that parcel.

In each partition $n$ beyond the $n_{\mathrm{o}}{ }^{\text {th }}$, for each square in the $n_{\mathrm{o}}$ partition, number consecutively all owners who have land in that square. For instance, in partition $n_{\mathrm{o}}+4$, each of the squares in the $n_{\mathrm{o}}$ partition will be divided into 16 smaller squares. The owners of these 16 squares making up a square of the $n_{\mathrm{o}}$ partition are to be numbered consecutively. (The numbering of owners whose land falls in different squares of the $n_{\mathrm{o}}$ partition does not matter.)

We know, therefore, that, for any partition $n$ beyond the $n_{\mathrm{o}}{ }^{\text {th }}$, if the government acquires its square parcel of side $k$ by making a price offer of $x$, the government must have succeeded in acquiring a run of subparcels covering an entire square of the $n_{\mathrm{o}}$ partition, where the probability of success for each parcel is $F(x)$. Since such a square in the $n_{\mathrm{o}}$ partition has area $1 / 2^{n_{\mathrm{o}}}$, the run must cover that area, so the length of the run must be $\left(1 / 2^{n_{\mathrm{o}}}\right) 2^{n}$, which is to say that $q=1 / 2^{n_{\mathrm{o}}}$.

(3) The optimal price offer for any partition $n$, denoted $x *(n)$, of the government must be below $s / c$ : If the offer is $s / c$ or above, then social welfare must be 0 or below if land is acquired, as the social cost of making payment is at least $c(s / c)=s$. Thus, such an offer cannot be optimal.

(4) The probability that the government succeeds in obtaining its parcel when it makes optimal price offers $x^{*}(n)$ tends to 0 as the number $n$ of partitions and of owners grows large: Let $Q(n)$ be the probability that the government succeeds in obtaining its parcel with respect to partition $n$ of the acre when it makes the optimal offer $x *(n)$. Let $P(n)$ be the probability that the government succeeds in obtaining its parcel with respect to partition $n$ of the acre if it makes the offer $s / c$. By step (3), $x^{*}(n)<s / c$, so that $Q(n)<$ $P(n)$. By steps (1) and (2), $\lim _{n \rightarrow \infty} P(n)=0$. Since $Q(n)<P(n), \lim _{n \rightarrow \infty} Q(n)=0$.

(5) The claimed results now follow for the reasons that Proposition 2(c)(iii) does. Namely, since the probability $Q(n)$ that the government obtains its parcel tends to 0 , social welfare under purchase tends to $E(v)$. But since social welfare under eminent domain is $s-c E(v)>E(v)$, if the partition $n$ is sufficiently high, social welfare under eminent domain exceeds social welfare under purchase. Also, the reason that the probability that government acquisition of a parcel of the type it seeks is socially desirable goes to 1 with $n$ is essentially that, as discussed after Proposition 2, the sample mean must tend in probability to $E(v)$ by the law of large numbers.

\section{Proposition 4.}

This is self-evident from the text except for the construction of the sequence of price offers $v(n)$, where $n$ is the number of landowners. To construct the price offers, first define for each positive integer $i$

$$
[s a-c a(v(a)+1 / i)]+\underset{v(a)+1 / i}{\int v f(v) d v .}
$$


This expression equals social welfare if area $a$ is purchased at a price of $v(a)+1 / i$. Let us show that if the price $v(a)+1 / i$ is offered, there is an $n(i)$ such that for all $n \geq n(i)$, social welfare must be within $.3 / i$ of (A13). By the law of large numbers, the probability that the fraction of acceptances of the price offer will be within any named distance $\epsilon$ of $F(v(a)+1 / i)$ tends to 1 with $n$. Choose $\epsilon$ to be .5 of $F(v(a)+1 / i)-a$, so that if the fraction of acceptances is within $\epsilon$ of $F(v(a)+1 / i)$, the fraction will exceed $a$ and the government will succeed in its acquisition. Hence, for any $p<1$, if $n$ is sufficiently high, the probability will be at least $p$ that the government will succeed, meaning that (A13) will give social welfare. It follows that, by choosing $p$ sufficiently close to 1 , social welfare must be within $.3 / i$ of (A13). Let $n(i)$ be the $n$ such that if $n$ is at least this high, $p$ is such that social welfare must be within .3/i of (A13).

Now define the sequence of prices $v(n)$. Let the prices be fixed at $v(a)+10$ for all $n$ until $n(1)$ is reached. At $n(1)$ let the price change to $v(a)+1$ and continue with this price until $n(1)+n(2)$ is reached. At $n(1)+n(2)$, let the price change to $v(a)+1 / 2$, and continue with this price until $n(1)+n(2)+n(3)$ is reached. At this point let the price change to $v(a)+1 / 3$, and so on. Notice therefore that when the price is $v(a)+1 / i$, it must be that $n$ exceeds $n(i)$, so that social welfare must be within $.3 / i$ of (A13).

By construction, we can say the following about the sequence of prices $v(n)$.

First, the prices are non-increasing, exceed $v(a)$, and tend to $v(a)$ in the limit (because $1 / i$ tends to 0 ).

Second, the limit of social welfare under the sequence is (16). To demonstrate this, consider any $d>0$. We wish to show that for all $n$ sufficiently high, social welfare must be within $d$ of (16). It is clear from (A13) that if $i$ is sufficiently high, then (A13) will be within $d / 2$ of (16) (because (A13) tends to (16) as $i$ increases). We also know that if $i$ is sufficiently high, social welfare if the price in the sequence is $v(a)+1 / i$ will be within $d / 2$ of (A13) (because social welfare is within $.3 / i$ of (A13)). Hence, if $n$ is sufficiently high, social welfare must be within $d / 2+d / 2$ or $d$ of (16).

Third, the probability of government success in acquiring $a$ using the sequence of prices tends to 1 . This must be true, for if it were not, then the limit of social welfare could not be (16). 